\title{
Spatial variability of soil organic carbon under different land use using radial basis function (RBF)
}

\author{
Gouri Sankar Bhunia $^{1} \cdot$ Pravat Kumar shit $^{2} \cdot$ Ramkrishna Maiti $^{3}$
}

Received: 16 October 2015/Accepted: 17 December 2015/Published online: 22 January 2016

(C) Springer International Publishing Switzerland 2016

\begin{abstract}
The present study was conducted to assess soil organic carbon (SOC) and other nutrients under different land use patterns in the lateritic region at Medinipur Block of Paschim Medinipur District, West Bengal, India. Samples were collected from different land use categories in 17 locations at soil depths of $0-19,20-39$, and $40-100 \mathrm{~cm}$. The physical and chemical properties of soil were measured and concentration of SOC, $\mathrm{pH}$, electric conductivity (EC), phosphorous $(\mathrm{P})$ and potassium $(\mathrm{K})$ were calculated for each depth and land use category. Statistical analyses, including simple correlation and principal component analysis (PCA) were used to relate land use and SOC data and other soil properties. The radial basis function (RBF) method was employed to investigate the spatial pattern of SOC. Spatial variability of SOC showed maximum concentration on the north west part and lowest concentration in the northeast and central parts of the study area. The maximum average value of SOC was highest at $0-19 \mathrm{~cm}$ depth and declined with increasing depth. The observed mean of SOC in the topsoil $(0-19 \mathrm{~cm})$ was highest in the forest soils $(0.69 \%)$ and lowest in fallow land $(0.41 \%)$. This study suggests a need for appropriate land use
\end{abstract}

Pravat Kumar shit

pravatgeo2007@gmail.com

1 Bihar Remote Sensing Application Center, IGSC-Planetarium, Adalatganj, Bailey Road, Patna 800001, Bihar, India

2 Department of Geography, Raja N.L.Khan Women's College, Gope Palace, Medinipur 721102, West Bengal, India

3 Department of Geography and Environment Management, Vidyasagar University, Medinipur 721102, West Bengal, India strategies and sustainable soil management for improving soil fertility in the study area.

Keywords Soil organic carbon - Radial basis function . Soil depth $\cdot$ Land use $\cdot$ Soil management

\section{Introduction}

Recognizing the technicalities of SOC is significant for decisive soil health, efficiency, and developing land control policies as well as carbon dioxide fluxes in the atmosphere. The conversion of land use/land cover (LULC) in southwest West Bengal (India) has significantly increased in order to meet growing demands for food and other products. Soil organic carbon (SOC) of an area determines the soil quality and constitutes one of the largest reservoirs of total global carbon stocks (Sheikh et al. 2011; Kumar et al. 2013). Commonly, it is noted that the carbon amassed in soils is almost three times that in the aboveground biomass and roughly two times that in the atmosphere (Post et al. 1990). Therefore, reinstatement of quality of soil via SOC management has remained the chief concern for tropical soils. The widespread use of chemical fertilizers adversely affects structure and texture, decreasing microbial activity and organic matter of soil (Das 2013; Zhuang et al. 2015). Variation in soil organic matter as a function of land use modification has been used to assess organic matter dynamics and to estimate carbon stocks and also carbon flux of the soil (Kalambukattu et al. 2013; Novara et al. 2013). Soil organic matter is the most important source and a provisional sink for plant nutrients in cultivated soils (Srinivasan et al. 2012).

The rapid decline of SOC by conversion of terrestrial ecosystem is well known (Post and Kwon 2000). Variations 
in soil organic matter fractions as a function of land use modification have been used to appraise organic matter dynamics and to estimate carbon stocks (Ashagrie et al. 2007; Galdos et al. 2009). Soil organic matter is the most important source of, and a provisional sink for, plant nutrients in cultivated soils (Srinivasan et al. 2012). The maintenance and buildup of the soil organic matter levels in agricultural areas is a major challenge in the very weathered soils of the tropical regions. This is due to different inputs of organic residues and fertilizers, which influence soil microbial activity and mineralization rates. Accordingly, LULC, mostly deforestation and deserted farmlands have become serious anxieties, as the insinuations for systems concerning human livelihoods are enormous (Durán Zuazo et al. 2013). Consequently, climatic factors, particularly temperature and precipitation are the key factors of SOC contents (Liu et al. 2011). However, balance of SOC can be disturbed by LULC change in anticipation of a new equilibrium is recognized within the altered ecosystem. Recently, several studies have confirmed the brawny impact of LULC types on SOC stores and their fractionation in different ecosystem (Durán Zuazo et al. 2014; Ayoubi et al. 2011). Investigating the spatial distribution of SOC is important for evaluating soil ecological functions and understanding soil carbon sequestration processes. Spatial Statistical approach appraise the autocorrelation usually observed in geographical data, where data values from locations close to each other are more analogous than data values from locations far apart (Isaaks and Srivastava 1989). Several studies also evaluated Kriging, inverse distance weighting (IDW) and radial basis functions (RBF) in soil science. Sarmadian et al. (2014) found that RBF method provide more accurate results than krigging and IDW interpolation technique. RBF methods predict values that can vary above the maximum or below the minimum of the measured values. The estimated values of the methods are based on a mathematical function that minimizes overall surface curvature, generating quite smooth surfaces (Karydas et al. 2009).

Intensive cultivation in dry land regions of Medinipur block (Pashim Medinipur) has resulted in the decline of its meager SOC pool at a fast rate exacerbated by climate change-related desertification processes. Distribution of different forms of SOC, phosphate and potash content in surface soil of rice fields in West Bengal was reported by Sarkar et al. (2013). As per the research report, it was found that $63-73 \%$ of inorganic $\mathrm{P}$ fraction of the total $\mathrm{P}$ in rice soils as against $37 \%$ in forest soil. No systematic study has been conducted to assess the SOC pool in the lateritic zone of West Bengal. Therefore, a pilot study was conducted to analyze the soil properties and spatial distribution of SOC under different land use using spatial statistical techniques.

\section{Materials and methods}

\section{Outline of study area}

The study was conducted in Medinipur of Paschim Medinipur district in West Bengal (India). It is extended between $22^{\circ} 23^{\prime} 45^{\prime \prime} \mathrm{N}-22^{\circ} 32^{\prime} 50^{\prime \prime} \mathrm{N}$ latitude and $87^{\circ} 05^{\prime} 40^{\prime \prime} \mathrm{E}-87^{\circ} 31^{\prime} 01^{\prime \prime} \mathrm{E}$ longitude covered with an area of $35,318.30$ ha (Fig. 1). The land surface area of the block is characterized by red lateritic cover, and flat alluvial and deltaic plains (Bhunia et al. 2012). The maximum temperature recorded in April is $43{ }^{\circ} \mathrm{C}$ and minimum temperature is $9{ }^{\circ} \mathrm{C}$ in the month of December. The average annual rainfall is about $1450 \mathrm{~mm}$ (Gayen et al. 2013).

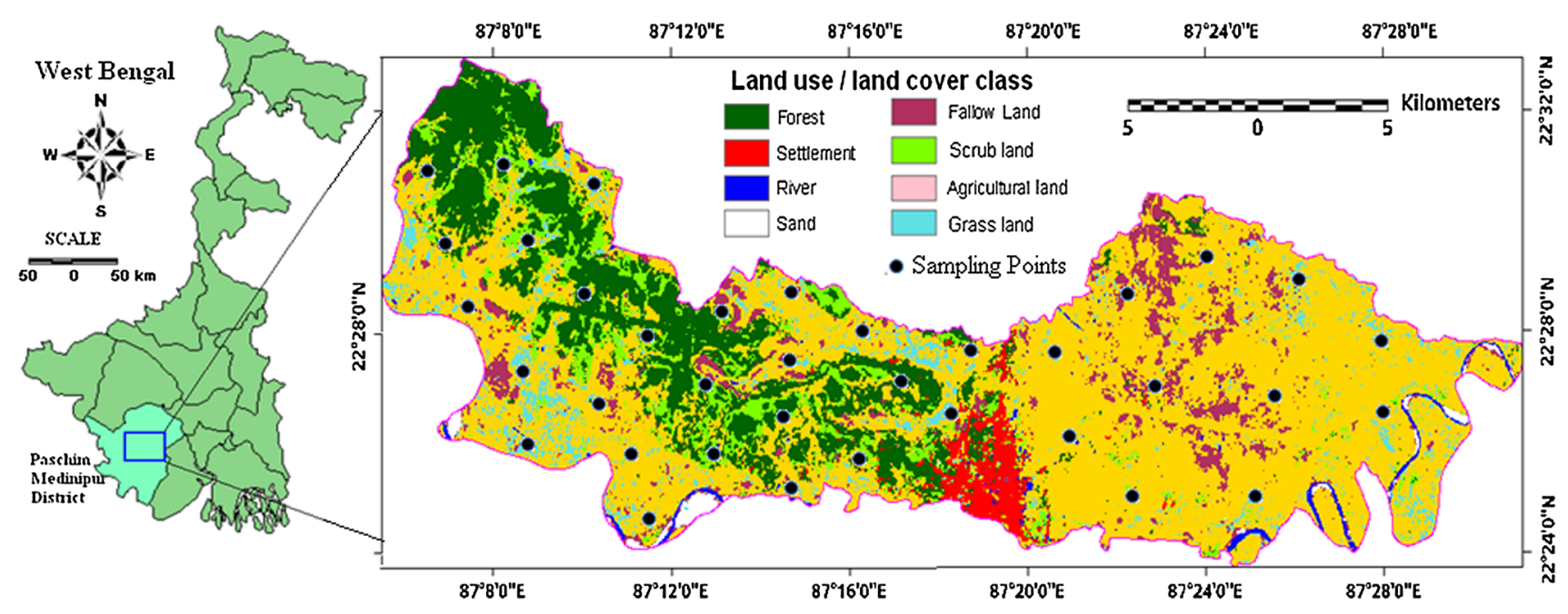

Fig. 1 Location of the study area and sampling design with land use land cover of Medinipur block derived from Landsat Thematic Mapper data 


\section{Soil sampling and analysis}

Stratified random sampling was used in the field during the post-monsoon season. Soil samples were collected at 17 sites under different land uses including agriculture (6), scrubland (3), forest (3), grassland (3), and fallow land (2) of the Medinipur block. A global positioning system (GPS) was used to locate each sample site (Fig. 1). In forest, the sampling was conducted in dense forest, degraded forest and open forest areas. River/water bodies, sand and urban regions were excluded from collection. Undisturbed soil samples at depths of $0-19$, 20-39, and 40-100 cm were collected with 5 soil cores from each site and mixed by depth into a composite soil sample. Soil samples were air dried and passed through a $2 \mathrm{~mm}$ sieve for laboratory analysis of soil texture, $\mathrm{pH}$, EC, P, K and SOC. Soil texture was measured using the mechanical sieve, soil $\mathrm{pH}$ was measured with a $\mathrm{pH}$-meter (Model: ML 962), and SOC concentration was determined by Walkely-Black wet oxidation method (Bao 2000). Soil available $\mathrm{P}$ was determined by spectrophotometer, following wet digestion in concentrated $\mathrm{H}_{2} \mathrm{SO}_{4}$ (Bremner 1996). Potassium was determined by flame spectrophotometer following wet digestion in $\mathrm{HF}^{-\mathrm{HClO}_{4}}$ (Knudsen et al. 1982).

\section{Statistical analysis}

Descriptive statistics of soil characteristics were analyzed. Principal components analysis was performed to investigate the interrelationship of pH, EC, P, K and SOC. Eigenvalues are the variances of the factors. PCA was used for data reduction. Each factor tends to have either positive or negative loadings of a large or small amount for any particular variable. Correlations between SOC and other soil properties were estimated using SPSS 12.0 software and MS Excel.

\section{Spatial statistical analysis}

Surface maps of SOC were prepared using the 'Geostatistical Analyst' of ArcGIS 8.1 software package through deterministic interpolation techniques. Deterministic interpolation method, degree of smoothing (radial basis functions, $R B F$ ) was used to generate the spatial distribution of SOC. The RBF method is considered as an exact interpolator where the surface passes through each measured sample value; projected values can fluctuate above the maximum or below the minimum of the measured sample values ( $\mathrm{Li}$ et al. 2007). The RBF model is used to predict the soil properties at unsampled locations. Earlier studies suggest that RBF is the best method to interpolate soil parameters and it is used to interpolate data points in a group of multi-dimensional space (Pal et al. 2014). RBF method is a family of five deterministic exact interpolation techniques: thin-plate spline (TPS), spline with tension (SPT), completely regularised spline (CRS), multiquadratic function (MQ and inverse multi-quadratic function (IMQ). RBF fits a surface through the measured sample values while minimizing the total curvature of the surface (Johnston et al. 2001). RBF is ineffective when there is a dramatic change in the surface values within short distances (ESRI, 2001, Xie et al. 2011). The most widely used RBF that is CRS was selected in this study (Arslan 2014).

\section{Validation}

Cross-validation technique was adopted for evaluating the performance of RBF interpolation methods. The sample points were arbitrarily divided into two datasets, with one used to train a model and the other used to validate the model. To reduce variability, the training and validation sets must cross-over in successive rounds such that each data point is able to be validated against. The root-mean-squared-error (RMSE) and the goodness of prediction were calculated as measures for accuracy and effectiveness respectively for all the produced topsoil prediction maps. The smallest RMSE values determine the suitability of a prediction model when its value tends to zero.

$R M S E=\sqrt{\frac{\sum_{i=1}^{N}\left(0_{i}-S_{i}\right)^{2}}{N}}$

where, $0_{i}$ is observed value and $\mathrm{S}_{\mathrm{i}}$ is the predicted value, $\mathrm{N}$ is the Number of samples.

\section{Result and discussion}

\section{Soil organic carbon (SOC)}

A relatively wide range of variation of SOC was observed at different soil depths (Table 1). Average SOC values for the whole study for the $0-19,20-39$ and $40-100 \mathrm{~cm}$ depths were $0.50,0.47$, and $0.43 \%$ respectively. The higher soil organic carbon, phosphate and potash content in surface soil of rice fields in West Bengal state mean value of SOC was found at $0-19 \mathrm{~cm}$ and decreased with increasing depth with variation from 0.08 to $0.99 \%$. However, the highest value $( \pm 0.39)$ of standard deviation of SOC was recorded at $20-39 \mathrm{~cm}$. The coefficient of variation $(\mathrm{CV} \%)$ of SOC was high at $0-39 \mathrm{~cm}$ and low at 40-100 cm depth. 
Table 1 Summary statistics from the classical analysis of soil organic carbon (SOC, \%) content in different soil horizons

\begin{tabular}{llllllllll}
\hline Soil depth $(\mathrm{cm})$ & $\mathrm{N}$ & Mean & Median & Min & Max & SD & CV $(\%)$ & Skewness & Kurtosis \\
\hline $0-19$ & 17 & 0.50 & 0.58 & 0.02 & 0.82 & 0.32 & 64.297 & 0.25 & 1.30 \\
20-39 & 17 & 0.47 & 0.52 & 0.05 & 0.87 & 0.39 & 81.79 & 0.02 & 1.59 \\
$40-100$ & 17 & 0.43 & 0.45 & 0.08 & 0.99 & 0.32 & 75.06 & 0.11 & 0.81 \\
\hline
\end{tabular}

$N$ number of samples, min minimum, max maximum, $S D$ standard deviation, $C V$ coefficient of variation

\begin{tabular}{lrlllll}
\hline $\mathrm{LC}^{\dagger}$ & Dep $^{\ddagger}$ & $\begin{array}{l}\mathrm{SOC} \\
(\%)\end{array}$ & $\begin{array}{l}\mathrm{pH} \\
-\end{array}$ & $\begin{array}{l}\mathrm{EC} \\
\mathrm{dSm}^{-1}\end{array}$ & $\begin{array}{l}\mathrm{P} \\
(\mathrm{kg} / \mathrm{hector})\end{array}$ & $\begin{array}{l}\mathrm{K} \\
(\mathrm{kg} / \mathrm{hector})\end{array}$ \\
\hline $\mathrm{Ag}$ & 0 & $0.47(0.12)$ & $5.7(0.42)$ & $0.18(0.03)$ & $500.8(2.53)$ & $210.6(63.64)$ \\
$\mathrm{Ag}$ & 20 & $0.41(0.26)$ & $5.85(0.21)$ & $0.18(0.01)$ & $500.0(2.54)$ & $196.2(89.1)$ \\
$\mathrm{Ag}$ & 40 & $0.19(0.48)$ & $6.10(0.14)$ & $0.19(0.05)$ & $496.0(9.19)$ & $263.0(86.5)$ \\
$\mathrm{Gr}$ & 0 & $0.55(0.51)$ & $6.08(0.53)$ & $0.24(0.05)$ & $500.8(2.07)$ & $160.38(92.4)$ \\
$\mathrm{Gr}$ & 20 & $0.43(0.51)$ & $6.28(0.59)$ & $0.25(0.07)$ & $500.7(3.5)$ & $171.4(77.2)$ \\
$\mathrm{Gr}$ & 40 & $0.40(0.38)$ & $6.31(0.48)$ & $0.27(0.10)$ & $499.9(1.80)$ & $84.15(51.4)$ \\
$\mathrm{Fo}$ & 0 & $0.69(0.23)$ & $6.28(0.29)$ & $0.24(0.05)$ & $502.0(1.46)$ & $189.3(70.89)$ \\
$\mathrm{Fo}$ & 20 & $0.61(0.35)$ & $6.07(0.27)$ & $0.28(0.11)$ & $501.4(1.85)$ & $193.3(86.3)$ \\
$\mathrm{Fo}$ & 40 & $0.42(0.26)$ & $6.05(0.29)$ & $0.23(0.04)$ & $502.0(1.47)$ & $216.0(57.4)$ \\
$\mathrm{Sc}$ & 0 & $0.50(0.1)$ & $5.83(0.38)$ & $0.20(0.04)$ & $500.21(2.07)$ & $255.36(28.61)$ \\
$\mathrm{Sc}$ & 20 & $0.35(0.38)$ & $5.90(0.20)$ & $0.21(0.02)$ & $501.4(2.07)$ & $197.28(88.17)$ \\
$\mathrm{Sc}$ & 40 & $0.31(0.37)$ & $6.17(0.06)$ & $0.37(0.23)$ & $501.4(2.07)$ & $183.0(78.46)$ \\
$\mathrm{Fa}$ & 0 & $0.41(0.23)$ & $6.10(0.1)$ & $0.26(0.04)$ & $501.4(2.07)$ & $202.8(76.1)$ \\
$\mathrm{Fa}$ & 20 & $0.37(0.52)$ & $6.03(0.15)$ & $0.22(0.03)$ & $502.0(1.15)$ & $163.93(50.04)$ \\
$\mathrm{Fa}$ & 40 & $0.13(0.30)$ & $5.93(0.23)$ & $0.21(0.04)$ & $501.0(2.07)$ & $160.0(117)$ \\
\hline
\end{tabular}

${ }^{\dagger}$ Land cover: $A g$ agriculture, $F o$ forest, $G r$ grassland, $S c$ scrub, $F a$ fallow

* Depth range: $0=0-19 \mathrm{~cm}, 20=20-39 \mathrm{~cm}, 40=40-100 \mathrm{~cm}$
Table 2 Characteristics of soil nutrients in different land use categories (mean and standard deviation)
Carbon stocks in the soil are affected by the accumulation and decay of organic matter in forest areas. Among the different horizons, forests had the highest and average SOC value in the upper horizon of soil (Table 1) and this amount decreased with increasing soil depth. Maximum average of SOC $(0.69 \%)$ was found in the top soil at $0-19 \mathrm{~cm}$ depth. The storage of carbon among the entire forest category under consideration was significantly higher in the top layer $(P<0.03)$. Briefly, a concentration of carbon sink was found in the 0-39 cm depth in all the forest soil samples in the study site. Storage of SOC in upper soil layer has been associated with the growth of root systems (Pillon 2000; Shit et al. 2010).

\section{Soil pH}

Assessment of $\mathrm{pH}$ of soils related to different land use types is shown in Table 2 . The average value of soil $\mathrm{pH}$ in the different horizons in the forest region varies from 4.2 6.9 indicating a moderate to slightly acidic nature (Table 2). Acidity increased as the depth of subsoil increased, which may be attributed to carbon dioxide from decomposing organic matter and root respiration dissolving in soil water to form a weak organic acid. The increase in soil $\mathrm{pH}$ on upper soil horizons of agricultural land may be attributed to soil submergence during the rice-growing period and use of the urea form of fertilizer. In grassland regions, soil $\mathrm{pH}$ varied from 6.01 to 6.31. In the upper horizon (0-19 cm depth), soils are slightly acidic in character whereas the acidity decreases with increasing depth. Moreover, average soil $\mathrm{pH}$ in shrub land regions varied from $5.83(0-19 \mathrm{~cm})$ to $6.17(40-100 \mathrm{~cm})$. Decrease of soil $\mathrm{pH}$ from the agricultural land might be due to exhaustion of basic cations or higher microbial oxidation that creates organic acids causing lower soil pH (Chauhan et al. 2014).

\section{Electrical conductivity (EC)}

Electrical Conductivity is increased by cropping, irrigation, and application of fertilizer and compost into land. The highest average value of EC $\left(0.28 \pm 0.11 \mathrm{dSm}^{-1}\right)$ was recorded at a depth of 20-39 cm (Table 2). Range of mean EC of soils in forest, agricultural land and grassland was $0.23-0.28,0.18-0.19$ and $0.24-0.27 \mathrm{dSm}^{-1}$ respectively. In shrub land, EC increased in trend with depth and varied between 0.20 and $0.37 \mathrm{dSm}^{-1}$. This may be accredited to 
Table 3 Principal component analysis to select the soil indicators as the minimum data set from studied soil samples $(n=51)$

\begin{tabular}{|c|c|c|c|}
\hline Soil depth $(\mathrm{cm})$ & Component & $\mathrm{PC} 1 *$ & $\mathrm{PC} 2 *$ \\
\hline \multirow[t]{8}{*}{$0-19$} & Eigenvalue & 2.146 & 1.909 \\
\hline & Variability (\%) & 42.92 & 38.18 \\
\hline & Cumulative (\%) & 42.92 & 81.09 \\
\hline & Variables & & \\
\hline & $\mathrm{pH}$ & -0.804 & 0.529 \\
\hline & $\mathrm{P}$ & -0.756 & -0.059 \\
\hline & $\mathrm{K}$ & 0.834 & 0.505 \\
\hline & EC & -0.388 & 0.763 \\
\hline \multirow[t]{8}{*}{ 20-39 } & Eigenvalue & 3.393 & 0.947 \\
\hline & Variability (\%) & 67.86 & 18.93 \\
\hline & Cumulative (\%) & 67.86 & 86.79 \\
\hline & Variables & & \\
\hline & $\mathrm{pH}$ & 0.927 & -0.296 \\
\hline & $\mathrm{P}$ & -0.751 & 0.194 \\
\hline & $\mathrm{K}$ & -0.777 & 0.451 \\
\hline & EC & 0.955 & 0.291 \\
\hline \multirow[t]{8}{*}{ 40-100 } & Eigenvalue & 2.24 & 1.788 \\
\hline & Variability (\%) & 44.89 & 35.77 \\
\hline & Cumulative (\%) & 44.89 & 80.65 \\
\hline & Variables & & \\
\hline & $\mathrm{pH}$ & -0.307 & 0.947 \\
\hline & $\mathrm{P}$ & 0.983 & 0.175 \\
\hline & $\mathrm{K}$ & 0.473 & -0.604 \\
\hline & $\mathrm{EC}$ & -0.824 & -0.037 \\
\hline
\end{tabular}

* Sign indicates load of variable either positive or negative on factor

variation of water content, salinity level, temperature and cation exchange capacity (CEC) (Doerge 1999). The low EC values of surface layer soils as compared to lower depths is probably due to leaching of salts from surface to subsurface layers because of poor internal drainage (Gurumurthy et al. 2009; Shit et al. 2010).

\section{Phosphorous (P) and Potassium (K)}

Phosphorous and $\mathrm{K}$ are essential nutrients for tree growth and significant variation among different land uses was found. The lowest value of $\mathrm{P}(501.40 \mathrm{~kg} / \mathrm{ha} \pm 1.85)$ is recorded at a depth of 20-39 $\mathrm{cm}$ among the horizons in the study area. The amounts of available $\mathrm{P}$ are slightly higher in the forest in comparison to agricultural land, grassland, shrub and fallow land (Table 2). The result corroborates the findings of Emiru and Gebrekidan (2013). In forest region, the amount of $\mathrm{K}$ is increased with depth. Moreover, the value of $\mathrm{K}$ was maximum at $40-100 \mathrm{~cm}$ depth in agricultural land while the lowest value of $\mathrm{K}$ was observed at $20-39 \mathrm{~cm}$ depth $(196.20 \mathrm{~kg} / \mathrm{ha})$. The total amount of $\mathrm{K}$ was the highest in the top organic layer and decreased gradually with increasing depth in the grassland, shrub and fallow land (Table 2). In grassland, the value of $\mathrm{K}$ varied from $160.38 \mathrm{~kg} / \mathrm{ha} \quad(0-19 \mathrm{~cm}$ depth $)$ to $84.15 \mathrm{~kg} / \mathrm{ha}$ (40-100 cm depth); whereas, in the shrub land the amount of K varied from $255.36 \mathrm{~kg} / \mathrm{ha}(0-19 \mathrm{~cm}$ depth) to $183 \mathrm{~kg} /$ ha $(40-100 \mathrm{~cm}$ depth). The value of $\mathrm{K}$ significantly increased with depth of the sub-soil horizon $(\mathrm{P}<0.004)$. The consistent decrease of available $\mathrm{K}$ from soil might have also caused low content of $\mathrm{K}$ in the pasture land and other cultivated land use systems (Wakene 2001).

The results of PCA showed that the first four PCs with eigenvalue $\geq 1$ accounted for $75 \%$ of the total variance (Table 3). Two factor of PCA was extracted. Within each PCA, the variable with the highest factor loading was selected as the most important contributor and strong relationship with the other variables. Results showed SOC has a positive load on $\mathrm{K}$, whereas $\mathrm{pH}, \mathrm{P}$, and $\mathrm{EC}$ have a negative load on the first factor at a depth of $0-19 \mathrm{~cm}$ depth. For the second factor, it was found that $\mathrm{pH}, \mathrm{K}$ and $\mathrm{EC}$ has a high positive load, while $\mathrm{P}$ has a lesser negative load. At a depth of 20-39 $\mathrm{cm}$ depth, $\mathrm{P}$ and $\mathrm{K}$ have negative load on SOC and positive load was found for $\mathrm{pH}$ and EC. However, the load has less in second factor for each variable except $\mathrm{K}$. In the $40-100 \mathrm{~cm}$ depth, results demonstrated that SOC has a positive load on $\mathrm{P}$ and $\mathrm{K}$; whereas, $\mathrm{pH}$ and $\mathrm{EC}$ have negative load. In second factor, $\mathrm{pH}$ has positive load and $\mathrm{K}$ has negative load in the study area.

\section{Spatial distribution of SOC}

The spatial distribution of SOC is shown in Fig. 2. The results showed small pockets of highest SOC in the central and extreme north-west corner at 0-19 cm depth (Fig. 2a) that corresponds to forest cover. The eastern and north-east corner of the study site has the minimum value of SOC as it is covered by fallow land. Most of the study area has medium values of SOC with mean error and RMSE values of 0.02 and 0.15 respectively. The analysis suggests that mainly in the topsoil $(0-19 \mathrm{~cm}$ depth) the geographical allocation patterns of SOC were extremely variable due to small scale variations in input, redistribution, and stabilization. The root-mean-square-error of the predictive model was 0.16 with the mean error of 0.007 of the predicted map of SOC at 20-39 cm depth (Fig. 2b). The central part of the study area is portrayed with medium value of SOC. The SOC prospect map at $40-100 \mathrm{~cm}$ depth was shows in Fig. 2c. The maximum SOC value was in the north-west part of the study site and small pocket was also observed in the northern part of the study site. The lowest value of SOC was observed in the central and north-east part of the Medinipur block with mean error and RMSE values are 0.07 and 0.18 respectively (Table 4). However, this study showed that the overall spatial distribution of the 

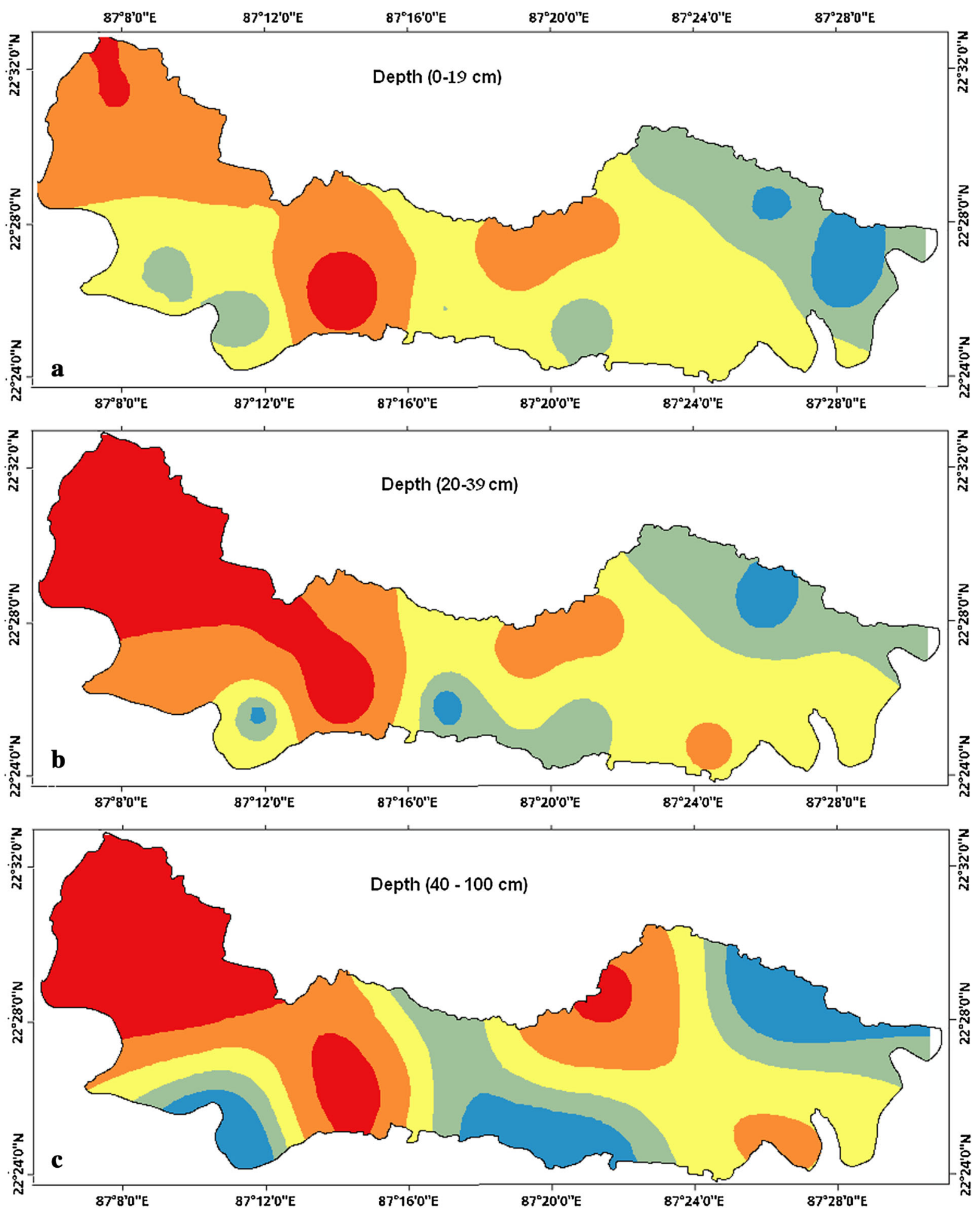

Scale

Legend

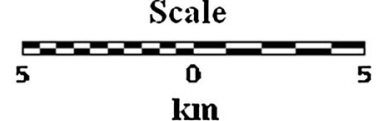

SOC (\%)

\begin{tabular}{l|l|l}
\hline$<0.25$ & $0.36-0.45 \square$ \\
$0.26-0.35$ & $0.46-0.55$ &
\end{tabular}


4Fig. 2 Spatial variability of SOC (\%) in Medinipur block at different depths interpolated by RBF model a 0-19 cm, b $20-39 \mathrm{~cm}$, c $40-100 \mathrm{~cm}$

Table 4 Parameters of the interpolation method (radial basis function) for SOC

\begin{tabular}{lllll}
\hline $\begin{array}{l}\text { Soil depth } \\
(\mathrm{cm})\end{array}$ & $\begin{array}{l}\text { Regression } \\
\text { function }^{\dagger}\end{array}$ & $\begin{array}{l}\text { Mean } \\
\text { error }\end{array}$ & RMSE & $\begin{array}{l}\text { Kernel } \\
\text { parameter }\end{array}$ \\
\hline $0-19$ & $\mathrm{Y}=0.08^{*} \mathrm{x}+0.28$ & 0.02 & 0.15 & 0.003 \\
$20-39$ & $\mathrm{Y}=0.45^{*} \mathrm{x}+0.24$ & 0.007 & 0.16 & 0.002 \\
$40-100$ & $\mathrm{Y}=0.49^{*} \mathrm{x}+0.31$ & 0.007 & 0.18 & 0.003 \\
\hline
\end{tabular}

$x$ explanatory variables, $Y$ dependent variables, $R M S E$ root mean square error

${ }^{\dagger}$ Kernel function completely regularized spline method

SOC in each layer of the study area was observed in patches or speckles and coefficient of variation of the SOC each layer was moderate variability.

\section{Conclusion}

Variation in land use systems and soil depth cause lessening in SOC and other soil nutrients responsible for soil productiveness and lead to soil degradation. The results derived through the RBF interpolation method were satisfactory for SOC prediction map. Agricultural land use led to a decrease in total soil organic carbon, but the value was higher than in the fallow land. Our results also portrayed that the forest region had ability for raising SOC to substantial levels while fallow land did not, possibly due to runoff and grazing in the study area. Consequently, the spatial variability of SOC portrayed the central and northeastern part of the study site as having the lowest level of SOC. Therefore, care should be taken to retain SOC in the north-eastern part of the study site. As the regional economy is based upon agriculture, local people depend on sustainable management of soil resources to support crops and pasture production. This means the organic carbon and other nutrients misplaced through agricultural uses should be refilled and put back into the system to retain nutrient stability. The amount of $\mathrm{P}$ and $\mathrm{K}$ among different land use categories were varied and insignificant in the lower soil layer in comparison to the surface soil layer which might be due to the surface soil layer being affected by different management practices.

A major limitation of the study is the small number of samples. However, the present study suggests the need for more comprehensive evidence and extended similar information for better monitoring and enhanced understanding of the impact of such changes in land use. The information derived in the study suggests the need to plan appropriate land use strategies and sustainable soil management and cultivation practices to combat the enduring soil degradation and improve soil fertility in the study area.

\section{References}

Arslan H (2014) Estimation of spatial distribution of groundwater level and risky areas of seawater intrusion on the coastal region in Çarşamba Plain, Turkey, using different interpolation methods. Environ Monit Assess 186(8):5123-5134

Ashagrie Y, Zech W, Guggenberger G, Mamo T (2007) Soil aggregation and total and particulate organic matter following conversion of native forests to continuous cultivation in Ethiopia. Soil Tillage Res 94:101-108

Ayoubi SP, Khormali F, Sahrawat KL, Rodrigues de Lima AC (2011) Assessment of soil quality indicators related to land use change in a loessial soil using factor analysis in Golestan Province, Northern Iran. J Agric Sci Tech 13:727-742

Bao SD (2000) Soil and agricultural chemistry analysis. China Agriculture Press, Beijing

Bhunia GS, Samanta S, Pal DK, Pal B (2012) Assessment of groundwater potential zone in paschim Medinipur district, West Bengal-a Meso-scale study using GIS and remote sensing approach. J Environ Earth Sci 2:41-59

Bremner JM (1996) Nitrogen-total. In: DL Sparks (ed) Methods of Soil Analysis. SSSA-ASA, Madison, pp 1085-1121

Chauhan RP, Pande KR, Thakur S (2014) Soil properties affected by land use systems in western Chitwan, Nepal. Int J Appl Sci Biotechnol 2(3):265-269

Das DC (2013) Comparative growth analysis of Callistephus chinensis L. using vermicompost and chemical fertilizer. Int $\mathbf{J}$ Bioassays 2(2):398-402

Doerge T (1999) Soil electrical conductivity mapping. Crop Insights 9(19):1-4

Durán Zuazo VH, Rodríguez Pleguezuelo CR, Francia MJR, Martín PFJ (2013) Land-use changes in a small watershed in the mediterranean landscape (SE Spain): environmental implications of a shift towards subtropical crops. J Land Use Sci 1:47-58

Durán Zuazo VH, Rodríguez Pleguezuelo CR, Cuadros Tavira S, Francia Martínez JR (2014) Linking soil organic carbon stocks to land-use types in a mediterranean agroforestry landscape. J Agr Sci Tech 16:667-679

Emiru N, Gebrekidan H (2013) Effect of land use changes and soil depth on soil organic matter, total nitrogen and available phosphorus contents of soils in Senbat watershed, western Ethiopia. ARPN J Agric Biol Sci 8(3):206-212

ESRI (2001) ArcGIS ${ }^{\mathrm{TM}}$ Geostatistical Analyst: Statistical Tools for Data Exploration, Modeling and Advanced Surface Generation. http://www.esri.com

Galdos MV, Cerri CC, Cerri CEP (2009) Soil carbon stocks under burned and unburned sugarcane in Brazil. Geoderma 153:347-352

Gayen S, Bhunia GS, Shit PK (2013) Morphometric Analysis of Kangshabati-Darkeswar Interfluves Area in West Bengal, India using ASTER DEM and GIS Techniques. J Geog Sci 2(4):1-10. doi:10.4172/2329-6755.1000133

Gurumurthy KT, Kiran KM, Prakasha HC (2009) Changes in physicchemical properties of soils under different land use systems, Karnataka. J Agric Sci 22(5):1107-1109

Isaaks E, Srivastava R (1989) Applied geostatistics. Oxford University Press, New York, p 561

Johnston K, Ver Hoef JM, Krivoruchko K, Lucas N (2001) Using ArcGIS Geostatistical Analyst. ESRI Press, Redlands 
Kalambukattu JG, Singh RD, Patra AK, Arunkumar K, Pote J (2013) Soil carbon pools and carbon management index under different land use systems in the Central Himalayan region. Acta Agric Scand Sect B-Soil Plant Sci 63(3):200-205. doi:10.1080/ 09064710.2012.749940

Karydas CG, Gitas IZ, Koutsogiannaki E, Lydakis-Simantiris N, Silleos GN (2009) Evaluation of spatial interpolation techniques for mapping agricultural topsoil properties in crete. EARSeL eProceedings 8

Knudsen D, Peterson GA, Pratt P (1982) Lithium, sodium, and potassium. In: Page AL (ed) Methods of Soil Analysis, Madison, Wis: American Society of Agronomy. Soil Sci Soc Am 2: 225-246

Kumar S, Lal R, Liu D, Rafiq R (2013) Estimating the spatial distribution of organic carbon density for the soils of Ohio, USA. J Geograph Sci 23(2):280-296

Li Y, Shi Z, Wu CF, Li HX, Li F (2007) Improved prediction and reduction of sampling density for soil salinity by different geostatistical methods. Agric Sci China 6:832-841

Liu Z, Shao M, Wang Y (2011) Effect of environmental factors on regional soil organic carbon stocks across the loess plateau region, China. Agric Ecosyst Environ 142:184-194

Novara A, Gristina L, LaMantia T, Rhul J (2013) Carbon dynamics of soil organic matter in bulk soil and aggregate fraction during secondary succession in a Mediterranean environment. Geoderma 193-194:213-221

Pal S, Manna S, Aich A, Chattopadhyay B, Mukhopadhyay SK (2014) Assessment of the spatio-temporal distribution of soil properties in East Kolkata wetland ecosystem (A Ramsar site: 1208). J Earth Syst Sci 123(4):729-740

Pillon CN (2000) Stocks and quality of soil organic matter as affected by no-till Cropping System. Doctorate thesis; Federal University of Rio Grande do Sul: Porto Alegre, pp 248
Post WM, Kwon KC (2000) Soil Carbon Sequestration and Land-Use Change: processes and Potential. Glob Change Biol 6:317-328

Post WM, Peng TH, Emmanuel WR, King AW, Dale VH, DeAngelis DL (1990) The global carbon cycle. Am Sci 78:310-326

Sarkar D, Mandal D, Haldar A (2013) Distribution and forms of Phosphorus in some red soils of Chotonagpur plateau, West Bengal. Agropedology 23(2):93-99

Sarmadian F, Ali K, Antonia O, Ghavamoddin Z, Hossein J (2014) Mapping of spatial variability of soil organic carbon based on radial basis functions method. ProEnvironment 7:3-9

Sheikh AM, Kumar M, Bussman RW, Todari NP (2011) Forest carbon stocks and fluxes in physiographic zones of India. Carbon Balance Manage 6(15):1-10

Shit PK, Pati CK, Jana SK (2010) Assessment of plant potential with relation to soil properties in different forest zones of Midnapur and Jhargram sub-divisions, West Bengal. Indian J Geograph Environ 11:64-71

Srinivasan V, Maheswarappa HP, Lal R (2012) Long term effects of topsoil depth and amendments on particulate and non particulate carbon fractions in a Miamian soil of Central Ohio. Soil Tillage Res 121:10-17

Wakene N (2001) Assessment of important hysicochemical properties of Dystric_Udalf (Dystric_Nitosols) under different management systems in Bako area, western Ethiopia. Thesis M.Sc. Alemaya University, Ethiopia. p 93

Xie Y, Chen T, Lei M, Yang J (2011) Spatial distribution of soil heavy metal pollution estimated by different interpolation methods: accuracy and uncertainty analysis. Chemosphere 82:468-476

Zhuang S, Haibao J, Zhang H, Sun B (2015) Carbon storage estimation of Moso bamboo (Phyllostachys pubescens) forest stands in Fujian, China. Trop Ecol 56(3):383-391 